

SPECTROSCOPY

\section{NMR without the magnet}

To obtain highly sensitive information on molecular structure and function, nuclear magnetic resonance (NMR) relies on a strong magnetic field. However, Alexander Pines at the University of California, Berkeley, and his co-workers have achieved high resolution and intense NMR spectra at zero magnetic field.

In conventional NMR, the external field partially aligns the nuclear spins in the molecule of interest. The authors' technique uses a polarizing agent to do roughly the same thing. The agent, parahydrogen, reacts with the molecule, inducing a greater degree of polarization of nuclear spins than conventional NMR, thereby enhancing the signal. The signals are then detected with a sensitive atomic magnetometer.

Using their technique, the authors were able to distinguish the structural features of several compounds. They say their method could be used as a low-cost, portable alternative to standard NMR machines.

Nature Phys. doi:10.1038/ nphys1986 (2011)

\section{ATMOSPHERIC SCIENCE}

\section{Methane rises} \section{from wetlands}

Natural tropical wetlands were the main source of a marked rise in global atmospheric methane levels observed during the past few years.

After a decade of stability, atmospheric concentrations of the potent greenhouse gas began to climb in 2007. Philippe Bousquet at the French National Centre for Scientific Research in Gif-surYvette, France, and his group

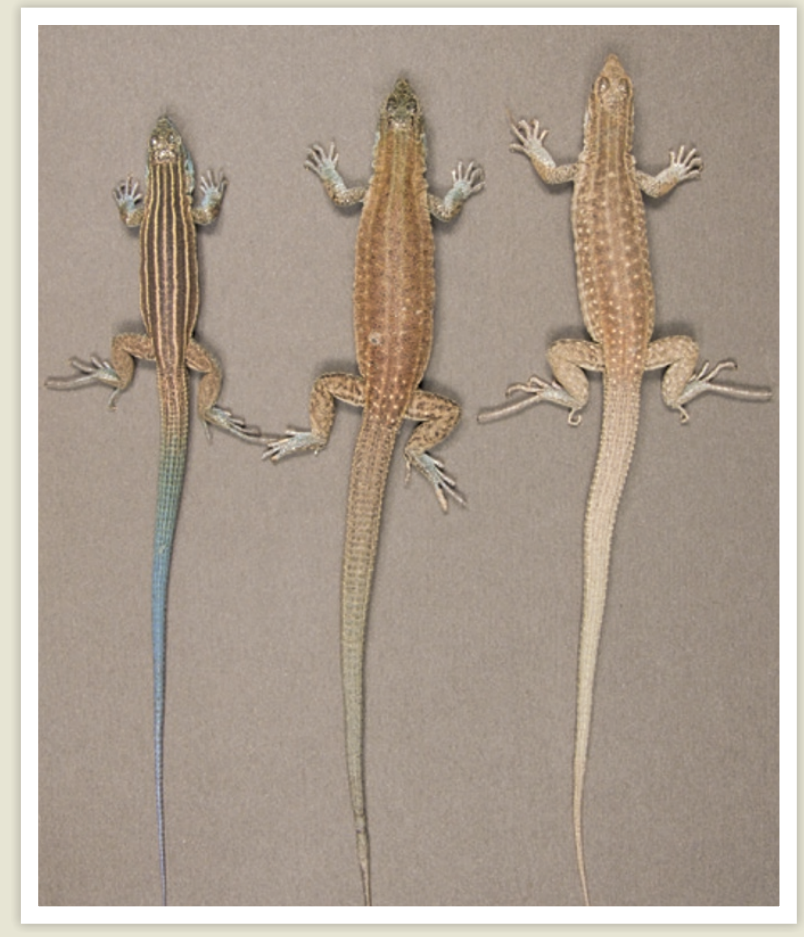

EVOLUTION

\section{To make a new species}

By mating a female lizard that has three sets of chromosomes with a male that has just the typical two, researchers have created a new species.

Several species of all-female whiptail lizard roam the deserts of New Mexico. They typically reproduce through an asexual process called parthenogenesis. But matings between all-female species and males of other species have, in the past, created 'triploid' hybrids - which have three sets of chromosomes - that then produced sterile offspring. Peter Baumann and his team at the Stowers Institute for Medical Research in Kansas City, Missouri, mated one of these triploid lizards (Aspidoscelis exsanguis; pictured right) with a male A. inornata lizard (left) to create a new species of whiptail (centre) that has four sets of chromosomes.

The tetraploid lizards went on to produce healthy, genetically identical daughters asexually. Surprisingly, the daughters could also reproduce in this way. The results may help to explain how species with more than two sets of chromosomes evolve.

Proc. Natl Acad. Sci. USA doi:10.1073/pnas.1102811108 (2011)

used atmospheric chemistry and transport models, along with an ecosystem model of wetland methane emissions, to infer the contributions of natural and anthropogenic sources to the rise.

They found that, in 2007, emissions from tropical wetlands accounted for two-thirds of the 21-milliontonne increase in methane over the 1999-2006 average. And, in 2008, the wetlands contributed about $50 \%$ of the 18-billion-tonne excess. The authors suggest that growth in wetland area due to increased rain is driving these elevated emissions.

Atmos. Chem. Phys. 11, 3689-3700 (2011)

\section{GENOMICS}

\section{Gene for malarial drug dodging}

A genome-wide study of malaria parasites has revealed a novel gene that confers drug resistance.

Pardis Sabeti at the Broad Institute in Cambridge, Massachusetts, and her team analysed 50 Plasmodium falciparum parasites from three continents and found 11 genes associated with resistance to antimalarial drugs. When they transferred one of these genes - which had not previously been associated with resistance — into parasites susceptible to drugs, the parasites became more resistant.

The protein encoded by the gene is located in the parasite's surface membrane, although its function is unknown. However, it does not seem to be a transporter protein such as those already known to pump drugs out of cells.

PLoS Genet. 7, e1001383 (2011)

\section{ORGANISMAL BIOLOGY}

\section{Sea urchins 'see' with their feet}

Sea urchins can respond to light despite having no obvious eye structure. Researchers have now pinpointed a possible mechanism for this, involving light-sensitive cells in the creatures' numerous tube feet.

Maria Arnone at the Anton Dohrn Zoological Station in Naples, Italy, and 